\title{
Esophageal atresia - associated anomalies and predictive factors of mortality
}

\author{
Ioana-Valentina Nenciu', Cristina-Adriana Becheanu ${ }^{2,5}$, Iulia Florentina Tincu ${ }^{3,5}$, \\ Ana Maria Bradeanu², Mihaela Balgradean ${ }^{4,5}$ \\ ${ }^{1}$ Medicover Hospital, Bucharest, Romania \\ 2"Grigore Alexandrescu" Emergency Clinical Hospital for Children, Bucharest, Romania \\ 3"Dr. Victor Gomoiu" Clinical Hospital for Children, Bucharest, Romania \\ 4"MS Curie" Emergency Clinical Hospital for Children, Bucharest, Romania \\ " "Carol Davila" University of Medicine and Pharmacy, Bucharest, Romania
}

\begin{abstract}
Introduction. Esophageal atresia (EA), typically occurring with tracheoesophageal fistula (TEF), is one of the most common digestive malformations; $50 \%$ of the esophageal atresia cases associate other malformations, syndromes or association of congenital abnormalities. EA is also met in patients with Edwards syndrome, Down syndrome, Di George syndrome and Pierre Robin syndrome. Delayed diagnosis of EA associated anomalies leads to increased morbidity and mortality, especially in patients with two or more associated abnormalities.

Our study aims to highlight EA associated anomalies and to evaluate their impact on mortality.

Materials and methods. We conducted a retrospective study of all newborns admitted in the Neonatal Intensive Care Unit of "Grigore Alexandrescu" Emergency Clinical Hospital for Children, with the diagnosis of esophageal atresia/ tracheoesophageal fistula (TEF), between January 2013 and December 2018; we evaluated demographic information, clinical manifestation, the ultrasound and radiological results. Our study aimed to highlight AE associated anomalies and to evaluate their impact on mortality.

Results. 56 newborns with esophageal atresia/ tracheoesophageal fistula diagnosis were identified. 31 of them were boys, and 22 patients had gestational age (GA) between 32 and 36 weeks. Five newborns came from twin pregnancies. EA/ TEF associated anomalies were identified in 35 patients; the most frequent of those were cardiac anomalies (identified in 25 patients). The association of 3 anomalies from VACTERL spectrum (vertebral, anorectal, cardiac, EA/ TEF, renal and urinary, and limb lesions) was seen in 11 newborns. The estimated risk of death was lightly increased in females and in patients from urban area; the patients with limb anomalies had an estimated risk of death 5 times higher $(p=0.043)$.

Conclusions. EA is a complex pathology both by the malformations and genetic syndromes that can be associated with it, and by the complications that occur in evolution. Antenatal diagnosis of EA and of the associated anomalies, along with multidisciplinary care, represent important measures in order to avoid underdiagnosis of associated problems.
\end{abstract}

Keywords: esophageal atresia, VACTERL, malformations

\section{INTRODUCTION}

Esophageal atresia, typically occurring with tracheoesophageal fistula, has a global incidence of 1 in 2,400 to 4,500 births and is one of the most common digestive malformations $(1,2)$; EA is $2-3$ times more frequent in twins (3).

Thomas Gibson documented the first case of EA in 1697 (3), and the first successful surgical intervention on EA was made by Cameron Haight in $1941(1,4)$.

The concern regarding morbidity and the quality of life of the patients with EA is increasing due to the progresses of the surgical techniques, the treatments given in the neonatal intensive care units, along with perfecting the nutrition techniques; all of this led to mortality decrease $(1,5)$. The newborns without severe congenital anomalies have a survival rate of $90 \%$. A higher mortality rate is noticed in premature newborns, with low birth weight, that develop sepsis or respiratory complications or in those with delayed diagnosis of EA/TEF (6).

In $50 \%$ of cases, EA associates other malformations - cardiac, gastrointestinal, renal and urinary, musculoskeletal or CNS anomalies - or association of 
congenital anomalies, such as VACTERL (vertebral, anorectal, cardiac, EA/TEF, renal and urinary, and limb lesions) or CHARGE (coloboma, cardiac defects, choanal atresia, growth failure, limb anomalies) $(3,7,8)$. EA is also met in patients with Edwards syndrome, Down syndrome, Di George syndrome and Pierre Robin syndrome $(2,8)$. Delayed diagnosis of EA associated anomalies leads to increased morbidity and mortality (9), especially in patients with two or more associated abnormalities (10).

Our study aims to highlight EA associated anomalies and to evaluate their impact on mortality.

\section{MATERIALS AND METHODS}

We conducted a retrospective study of all newborns admitted in the Neonatal Intensive Care Unit of "Grigore Alexandrescu" Emergency Clinical Hospital for Children, with the diagnosis of esophageal atresia / tracheoesophageal fistula (TEF), between January 2013 and December 2018. Patients with incomplete data were excluded. From the hospital's informatic system and archive we collected information such as demographic information, clinical manifestation, ultrasound and radiological results, treatment protocols, complications that occurred during the hospitalization. Data were analyzed with Microsoft ${ }^{\circledR}$ Excel (ver. 16.15) and IBM ${ }^{\circledR}$ SPSS ${ }^{\circledR}$ Statistics (ver. 18). Associated anomalies were diagnosed by clinical examination, ultrasound and radiological tests.

\section{RESULTS}

\section{General characteristics}

56 newborns with esophageal atresia/ tracheoesophageal fistula diagnosis were included in the study. 6 patients were excluded due to incomplete data. In table 1 we present the epidemiological data of the subjects.

TABLE 1. Characteristics of the study group

\begin{tabular}{|c|c|c|}
\hline Parameter & $\mathrm{n}$ & $\%$ \\
\hline Gender & 31 & 55.4 \\
\hline male & 25 & 44.6 \\
\hline \multicolumn{2}{|c|}{ Environment } & 58.9 \\
\hline urban & 33 & 41.1 \\
\hline rural & 23 & \\
\hline Gestational age & 1 & 2.0 \\
\hline$<28$ weeks & 3 & 44.0 \\
28-31 weeks & 22 & 48.0 \\
\hline $32-36$ weeks & 24 & \\
\hline 36 weeks & & \\
\hline Birth weight & & \\
\hline
\end{tabular}

\begin{tabular}{|c|c|c|}
\hline AGA & 49 & 87.5 \\
SGA & 7 & 12.5 \\
\hline Type of pregnancy & & \\
\hline twin & 5 & 8.92 \\
singleton & 51 & 91.08 \\
\hline Deceased & & \\
\hline yes & 13 & 23.2 \\
no & 43 & 76.8 \\
\hline
\end{tabular}

31 of them were boys and 33 were from urban area. More than $50 \%$ were premature: 22 had GA between 32 and 36 weeks and one had GA lower than 28 weeks. Only 7 newborns were small for gestational age (SGA). Five patients came from twin pregnancies. Just one patient had only EA, without TEF or other anomalies, and 35 had EA+TEF and other associated abnormalities. Three newborns had EA without TEF, 51 had distal TEF and 2 had both proximal and distal TEF.

The association of 3 anomalies from VACTERL spectrum was identified in 11 newborns (19.6\%), two of them came from twin pregnancies (table 2).

TABLE 2. VACTERL association in EA patients

\begin{tabular}{|l|l|}
\hline VACTERL association - TEF with: & $\begin{array}{l}\text { Another associated } \\
\text { anomalies }\end{array}$ \\
\hline $\begin{array}{l}\text { Anal imperforation with recto-vaginal } \\
\text { fistula + ASD + } \\
\text { Persistent left SVC + left radial aplasia }\end{array}$ & coloboma \\
\hline $\begin{array}{l}\text { Thoracal hemivertebra + dextrocardia + } \\
\text { lower right limb malformation }\end{array}$ & \\
\hline $\begin{array}{l}\text { Anal imperforation with recto-vaginal } \\
\text { fistula + septal interatrial aneurysm + } \\
\text { right kidney hydronephrosis }\end{array}$ & \\
\hline $\begin{array}{l}\text { PDA + Persistent left SVC + left kidney } \\
\text { hydronephrosis }\end{array}$ & \\
\hline $\begin{array}{l}\text { Persistent left SVC + dilated heart } \\
\text { cavities + left kidney hydronephrosis }\end{array}$ & \\
\hline $\begin{array}{l}\text { Anal imperforation with recto-vaginal } \\
\text { fistula + bilateral radial aplasia }\end{array}$ & $\begin{array}{l}\text { Duodenal stenosis by } \\
\text { incomplete diaphragm }\end{array}$ \\
\hline $\begin{array}{l}\text { Anal imperforation with recto-vaginal } \\
\text { fistula + left kidney hydronephrosis + } \\
\text { right kidney multichystic dysplasia + right } \\
\text { radial aplasia + left hand abnormalities }\end{array}$ & \\
\hline $\begin{array}{l}\text { Persistent left SVC + left kidney } \\
\text { hydronephrosis }\end{array}$ & \\
\hline Left L2 hemivertebra + ASD & Common mesentery \\
\hline $\begin{array}{l}\text { Anal imperforation with recto-vaginal } \\
\text { fistula + VSD }\end{array}$ & \\
\hline $\begin{array}{l}\text { Anal imperforation with recto-vaginal } \\
\text { fistula + ASD+ VSD }\end{array}$ & \\
\hline
\end{tabular}

The other associated abnormalities are presented in table 3; cardiac anomalies were the most common (identified in 25 patients). 
TABLE 3. Other EA associated anomalies

\begin{tabular}{|c|c|c|}
\hline & $\mathrm{n}$ & $\%$ \\
\hline coloboma & 1 & 1.8 \\
\hline trisomy 18 & 1 & 1.8 \\
\hline duodenal atresia & 1 & 1.8 \\
\hline dextrocardia & 2 & 3.6 \\
\hline Tetralogy of Fallot & 1 & 1.8 \\
\hline $\begin{array}{l}\text { other cardiac abnormalities } \\
\circ \text { ASD } 5 \\
\circ \text { VSD } 4 \\
\circ \text { VSD + ASD } 1 \\
\circ \text { PDA } 1 \\
\circ \text { ASD + PDA } 1 \\
\circ \text { SIA aneurysm } 1 \\
\circ \text { SIA aneurysm + ASD } 2 \\
\circ \text { persistent left SVC } 2 \\
\circ \text { persistent left SVC + VSD } 1 \\
\circ \text { persistent left SVC + ASD } 2 \\
\circ \text { persistent left SVC + PDA } 1 \\
\circ \text { persistent left SVC + dilated heart cavities } 1\end{array}$ & 22 & 39.3 \\
\hline single umbilical artery & 2 & 3.6 \\
\hline single umbilical artery and palatochisis & 1 & 1.8 \\
\hline duodenal stenosis by incomplete diaphragm & 1 & 1.8 \\
\hline common mesentery & 1 & 1.8 \\
\hline cerebral and cerebellar atrophy & 1 & 1.8 \\
\hline congenital tracheomalacia & 3 & 5.4 \\
\hline right kidney agenesis & 3 & 5.4 \\
\hline left kidney agenesis & 2 & 3.6 \\
\hline
\end{tabular}

\section{Prognostic factors}

Almost a quarter of patients died during the first hospitalization. The estimated risk of death was lightly increased in females (RR $=1.29$; IC95\%: 0.70 $2.38 ; \mathrm{p}=0.450)$ and in patients from urban area $(\mathrm{RR}=1.12$; IC95\%: 0.42-2.98; $\mathrm{p}=0.827)$. The death ocurred more frequent at GA between 32 and 36 weeks $(69.2 \%$ vs $35.1 \%)$, with a relative risk twice higher ( $R R=2.29$; IC95\%: 1.28-4.09; 0.012). The patients with limb anomalies had an estimated risk of death 5 times higher $(\mathrm{RR}=4.96$; IC95\%: 0.96-26.6; $\mathrm{p}$ $=0.043$ ) (table 4). Newborns with vertebral defects had an average number of hospitalization days significantly higher (30.75 vs. 13.50 days; $\mathrm{p}=0.05$ ).

TABEL 4. Predictive factors of mortality in EA patients

\begin{tabular}{|l|c|c|c|c|c|c|c|c|}
\hline \multirow{2}{*}{ Parameters } & \multicolumn{2}{|c|}{$\begin{array}{c}\text { Death } \\
\text { (n= 13) }\end{array}$} & \multicolumn{2}{c|}{$\begin{array}{c}\text { Survival } \\
(\mathbf{n}=\mathbf{4 3})\end{array}$} & \multirow{2}{*}{ OR } & \multirow{2}{*}{$\mathbf{p}$} & RR & \multirow{2}{*}{ IC95\% } \\
\cline { 2 - 7 } & $\mathbf{n}$ & $\mathbf{\%}$ & $\mathbf{n}$ & $\mathbf{\%}$ & & & & \\
\hline Female & 7 & 53.8 & 18 & 41.9 & 1.62 & 0.450 & 1.29 & $0.70-2.38$ \\
\hline Urban area & 8 & 61.5 & 25 & 58.1 & 1.15 & 0.827 & 1.12 & $0.42-2.98$ \\
\hline $\begin{array}{l}\text { GA 32-36 } \\
\text { weeks }\end{array}$ & 9 & 69.2 & 13 & 35.1 & 5.19 & 0.012 & 2.29 & $1.28-4.09$ \\
\hline AGA & 11 & 84.6 & 38 & 88.4 & 0.72 & 0.725 & 0.79 & $0.22-.2 .83$ \\
\hline Distal TEF & 12 & 92.3 & 39 & 90.7 & 1.23 & 0.859 & 1.02 & $0.85-1.22$ \\
\hline $\begin{array}{l}\text { Vertebral } \\
\text { defects }\end{array}$ & 1 & 7.7 & 1 & 2.3 & 3.50 & 0.365 & 3.31 & $0.22-49.3$ \\
\hline
\end{tabular}

\begin{tabular}{|l|c|c|c|c|c|c|c|c|}
\hline \multirow{2}{*}{ Parameters } & \multicolumn{2}{|c|}{$\begin{array}{c}\text { Death } \\
\text { (n= 13) }\end{array}$} & \multicolumn{2}{c|}{$\begin{array}{c}\text { Survival } \\
\text { (n= 43) }\end{array}$} & OR & p & RR & IC95\% \\
\cline { 2 - 8 } & $\mathbf{n}$ & $\%$ & $\mathbf{n}$ & $\%$ & & & & \\
\hline $\begin{array}{l}\text { Cardiac } \\
\text { anomalies }\end{array}$ & 3 & 23.1 & 22 & 51.2 & 0.29 & 0.067 & 0.45 & $0.16-1.27$ \\
\hline $\begin{array}{l}\text { Anal } \\
\text { anomalies }\end{array}$ & 1 & 7.7 & 5 & 11.6 & 0.68 & 0.740 & 0.71 & $0.09-5.53$ \\
\hline $\begin{array}{l}\text { Renal } \\
\text { anomalies }\end{array}$ & 3 & 23.1 & 7 & 16.3 & 1.54 & 0.578 & 1.42 & $0.42-4.71$ \\
\hline $\begin{array}{l}\text { Limb } \\
\text { anomalies }\end{array}$ & 3 & 23.1 & 2 & 4.7 & 6.15 & 0.043 & 4.96 & $0.96-26.6$ \\
\hline
\end{tabular}

\section{DISCUSSION}

Identification of patients with EA/TEF associated anomalies is highly important for establishing the appropriate therapeutic behavior for these children, as well as for prenatal and postnatal counseling of parents.

VACTERL association in EA patients was correlated in the literature with a higher mortality. The reports regarding VATERL association and other congenital abnormalities in EA patients are based on single institutional experiences, using differing criteria, making comparisons difficult (11).

In the study we presented, EA had a higher incidence in male newborns and in premature ones; this results are consistent with the literature reports. In a study made by Li WX et al. (6), which aimed to establish a scoring system for predicting mortality in EA patients, prematurity was a predictive factor for mortality ( $\mathrm{p}<0.003$ ); there was no correlation between gender and mortality.

Both the preponderance of EA associated anomalies (35 out of 56 patients) and the preponderance of cardiac anomalies ( 25 out of 56 patients) are in concordance with the data described in the literature; however, our study did not show correlations between cardiac anomalies and mortality. This result is explained by the predominance, in our study group, of cardiac anomalies without an important hemodynamic impact.

VACTERL association was lower compared to the data described in other studies $-19.6 \%$ vs $33.4 \%$, value reported by Lautz et al. in a study conducted on 2,689 EA patients (11). Reported in the same study, spinal/vertebral anomalies were much lower $-0.03 \%$ ( 2 patients with hemivertebra in our study) vs. $24.4 \%$ - the percentage of all spinal anomalies - and $5.2 \%$ of those with hemivertebra.

Anomalies from VACTERL spectrum were associated with an increased death risk - patients with limb abnormalities had an estimated risk of death 5 times higher $(\mathrm{RR}=4.96$; IC95\%: 0.96-26.6; $\mathrm{p}=0.043)-$ 
and with a prolonged hospitalization: newborns with vertebral defects had an average number of hospitalization days significantly higher (30.75 vs. 13.50 days; $p=0.05$ ). 6 out of 11 patients with VACTERL association were born before 37 weeks of gestation. The death rate among patients with VACTERL association was slightly higher compared to those without this association ( $27 \%$ vs. $22 \%)$; this information also corresponds to those in the literature.

The research presented has the advantage to present the results from a tertiary center of pediatric surgery, with extensive experience regarding the newborn surgical pathology; also, the results regarding associated abnormalities correspond to those in the literature.

One of the limitations of the study is represented by its retrospective character, by processing the data from the informatic system and from the hospital archieve; the small number of patients included in the

\section{REFERENCES}

1. Krishnan U, Mousa H, Dall'Oglio L, Homaira N, Rosen R, Faure C, Gottrand F. ESPGHAN-NASPGHAN Guidelines for the Evaluation and Treatment of Gastrointestinal and Nutritional Complications in Children With Esophageal Atresia-Tracheoesophageal Fistula. JPGN. 2016;63:550-70.

2. Patria MF, Ghislanzoni $S$, Macchini $F$ et al. Respiratory morbidity in children with repaired congenital esophageal atresia with or without tracheoesophageal fistula. Int J Environ Res Public Health. 2017;14(10):E1136.

3. Spitz L. Oesophageal atresia. Orphanet J Rare Dis. 2007;2:24.

4. Okuyama H, Tazuke Y, Uenoa T et al. Long-term morbidity in adolescents an young adults with surgically treated esophageal atresia. Surg Today. 2017;47:872-76.

5. Rayyan M, Embrechts M, Van Veer $\mathrm{H}$ et al. Neonatal factors predictive for respiratory and gastro-intestinal morbidity after esophageal atresia repair. Pediatr Neonatol. 2019;60:261-269.

6. Li XW, Jiang YJ, Wang XQ et al. A scoring system to predict mortality in infants with esophageal atresia: A case control study. Medicine (Baltimore). 2017;96:32. study probably limited the number of associated malformations.

\section{CONCLUSION}

Esophageal atresia is a complex pathology both by the malformations and genetic syndromes that can be associated with it, and by complications that occur in evolution. Antenatal diagnosis of EA and associated abnormalities, along with the care of EA patients by multidisciplinary teams, are essential measures to avoid underdiagnosis of associated problems, to reduce morbidity and adverse effects of complications, and to improve the patient's quality of life. The inclusion of EA/TEF patients in national evidence programs and the development of protocols aiming the clinical and paraclinical follow-up of these patients represent absolutely necessary measures.

Conflict of interest: none declared Financial support: none declared

7. Traini I, Menzies J, Hughes J et al. Oesophageal atresia: The growth gap. World J Gastroentero. 2020;26(12):1262-1272.

8. Blanco AJ, Gutierrez Velez A, Solis-Garcia G, Salcedo Posadas A et al. Comorbidities and course of lung function in patients with congenital esophageal atresia. Arch Argent Pediatr. 2020;118(1):2530 .

9. Sharma S, Pathak S, Husain A et al. Associated congenital anomalies with esophageal atresia and their impact on survival in an indian scenario. Int J Contemp Med Res. 2016;3:1626-1628.

10. Singh A, Middlesworth W, Khlevner J. Surveillance in patients with esophageal atresia/ tracheoesophageal fistula. Curr Gastroenterol Rep. 2017;19:4.

11. Lautz TB, Mandelia A, Radhakrishnan J. VACTERL associations in children undergoing surgery for esophageal atresia and anorectal malformations: Implications for pediatric surgeons. J Pediatr Surg. 2016;50:1245-1250. 